Vol. XXII, No. 1

\title{
More Plants of the Dry Prairie and Hillsides
}

by K. F. Best, Swift Current

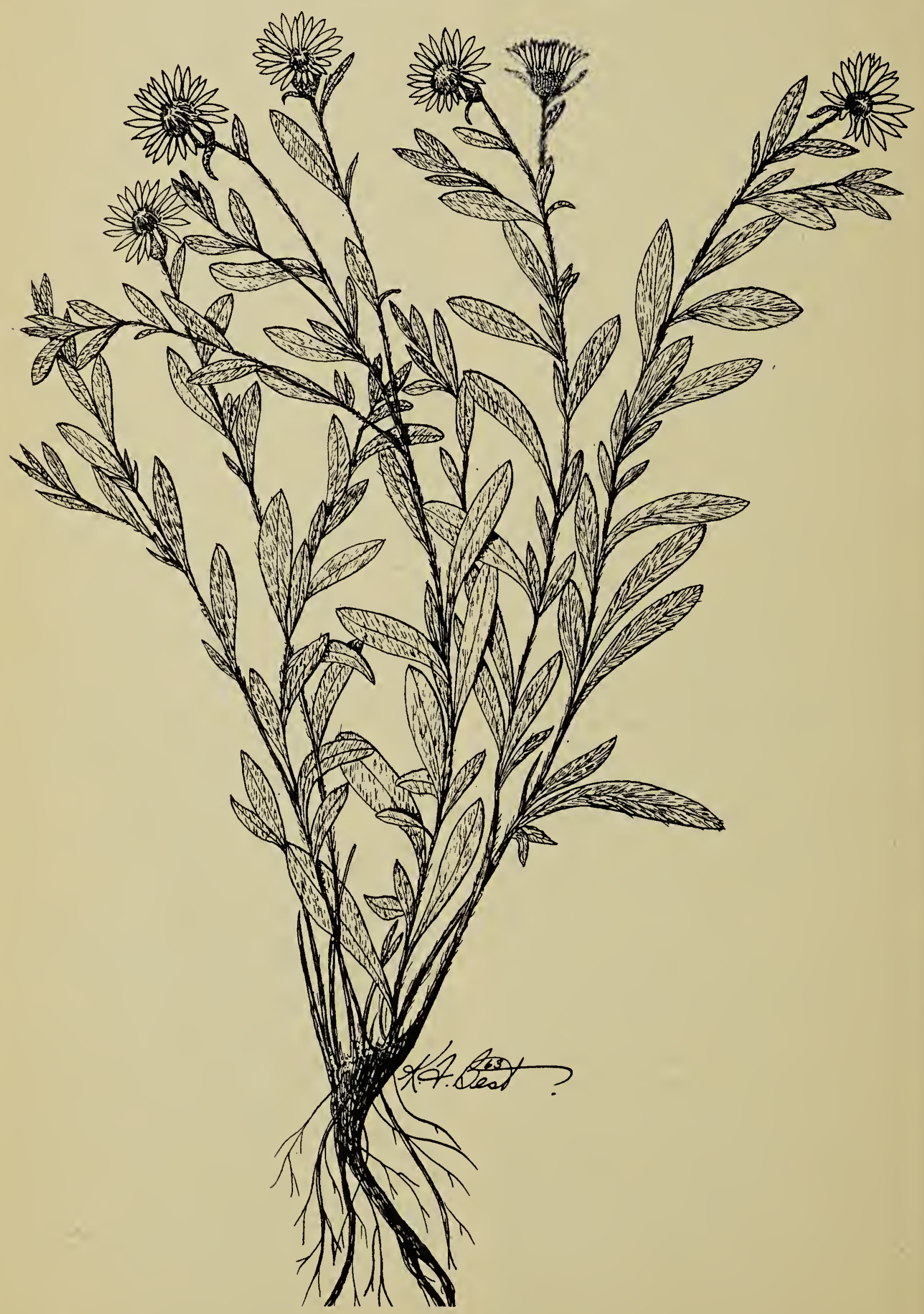

Fig. 1. Hairy Golden-aster 
In our series, we have moved from the dunelands through the sandhills and on to the eroded hillsides and drier portions of the open prairie. Owing to the wealth of vegetation which often goes unnoticed in these areas, we find ourselves with a multitude of species to describe, but it is difficult to find satisfactory headings under which to group them. In this issue we have a golden-aster and a goldenrod, both representative of the large family known as Compositae.

The golden-asters are a relatively small genus of about 30 or more species of herbaceous plants native to North America. The genus was christened Chrysopsis because of its yellow flowers, the name being derived from the Greek chrysos, gclden, and opsis, aspect. The flowers resemble those of the Aster species, but may be distinguished by the golden tint of the outer or ray florets of the head-hence the common name of golden-aster.

These plants thrive on dry, frequently sandy or rocky locations in full sunlight. The strong, deep taproots often penetrate to depths in excess of eight feet and aid in maintaining their existence in dry places. The deep root penetration and the ability to grow on poorer, dry soils ,nakes them valuable as soil binders. Although often abundant, they do not cccur in pure stands. In some semidesert areas these plants may provide fair forage for sheep, but under normal range conditions are usually listed as worthless for all classes of livestock.

Hairy golden-star (Chrysopsis villosa) is a perennial growing from a a branching woody taproot to a height of from six to 24 inches. The branching stems are covered with coarse, stiff hairs, and the grayishgreen alternate leaves are one to two inches long with short, stiff, appressed hairs. Sometimes the lower leaves have short stalks, but the upper leaves are generally stalkless. Flower heads are not numerous, radiate, about one inch across, and have bright yellow ray florets. Seeds are hairy achenes with a double pappus, the inner consisting of rough hairs, and the outer of small scales or minute bristles. Common on dry sandy prairies and hillsides, especially in southern portions.

The goldenrods are a large genus, including scme 130 species of the sunflower family. Attention was focused on the genus by the late Thomas A. Ediscn, when he discovered its slight rubber content. In ancient times certain species of goldenrod were supposed to have wound-healing properties. The generic name Solidago, from the Latin solidus and ago, to unite firmly, comes from this purported use and value. Goldenrods have come in for much abuse from hay fever sufferers, but, actually, very little hay fever is caused by them. Their pcllen, adapted for transport by insects, is heavy and sticky, and is produced rather sparingly. It is not carried by the wind. Most hayfever ascribed to goldenrod pollen is really caused by the light, dry, airborne pollen of the ragweeds and mugwort, which produce pollen in tremendous quantities for air transport and shed it when the goldenrods are in flower.

Most of our goldenrods are relatively low in forage value.

Velvety goldenrod (Solidago mollis) is an erect perennial herb, eight to 18 inches in height with alternate, almcst entire leaves. The plant is covered with short, very fine velvety hairs. The pale green leaves are three-nerved, from one to three inches long, the upper ones being much reduced. The inflorescence is a pyramid-shaped dense panicle of radiate yellcw flower heads. The pappus consists of one or two series of rough, bristly hairs. It is common on dry prairie land and roadside, and is probably the most common species in these areas.

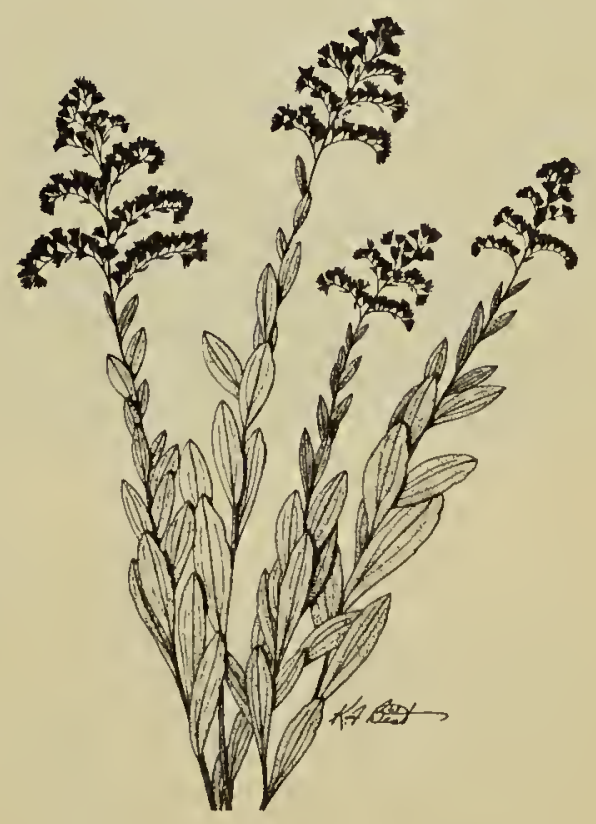

Fig. 2. Velvety Goldenrod 